\title{
Distribution of some Oceanic Birds in the Waters East of New Zealand.
}

By Dr. P. Jespersen, Copenhagen.

$\mathrm{T}$ HE Danish Research Ship Dana, sent out for a two years' expedition around the world by the Carlsberg Foundation in Copenhagen, under the leadership of Prof. Johs. Schmidt, director of the Carlsberg Laboratory, spent the months of December 1928 and January 1929 in New Zealand waters. From Jan. 2 to Jan. 13 investigations were carried out in the waters east of New Zealand on a cruise, going out from Auckland in a southerly direction to a position situated about $49^{\circ} \mathrm{S}$. Lat. and $177^{\circ} \mathrm{E}$. Long., from there going west to about $172^{\circ}$ E. Long. and farther north along the east coast of the South Island to Wellington.

On the whole circumnavigating expedition of the Dana, observations of the bird-life were made on the high sea, but as we on the above-mentioned cruise in New Zealand waters had the New Zealand zoologist, Mr. R. A. Falla, a keen and clever ornithologist, on board the Dana as guest, the ornithological observations on this cruise were made with a higher degree of accuracy than in ordinary circumstances. In very few areas of the world are the birds belonging to the order Tubinares represented by so many different species as in the New Zealand waters, and as Mr. Falla has especially studied these birds, it is first of all due to Mr. Falla's knowledge about these oceanic birds that the

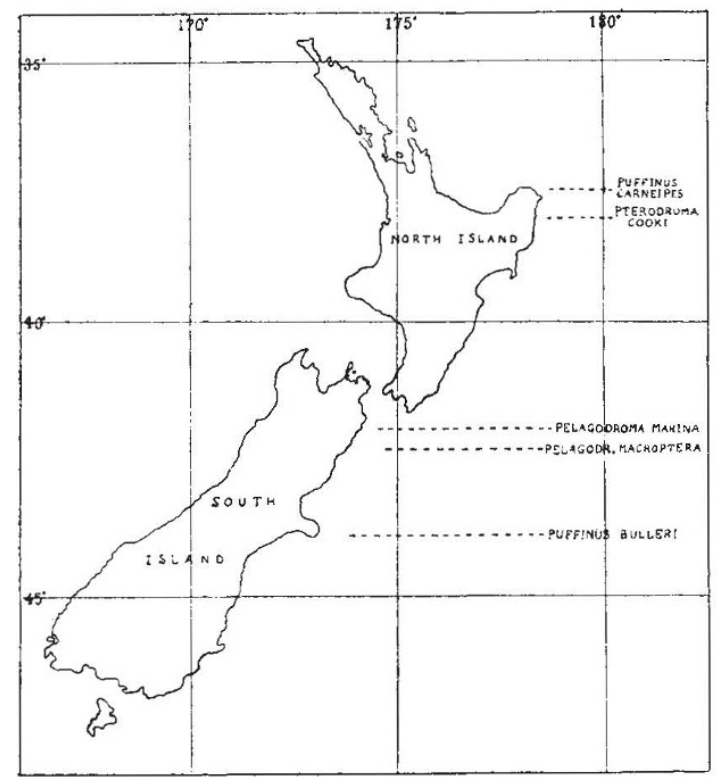

FIG. 1.-Map showing the southern limit for northern breeding species of birds.

ornithological observations were so extensive on this particular cruise.

Our most important task was to determine, so far as possible, the limits for the distribution of the various species of birds in the open sea, and in the following a brief account of the result of our investigations will be given, especially in regard to the distribution of the various species from north to south. It must, however, be remembered that the results apply only to the month of January,

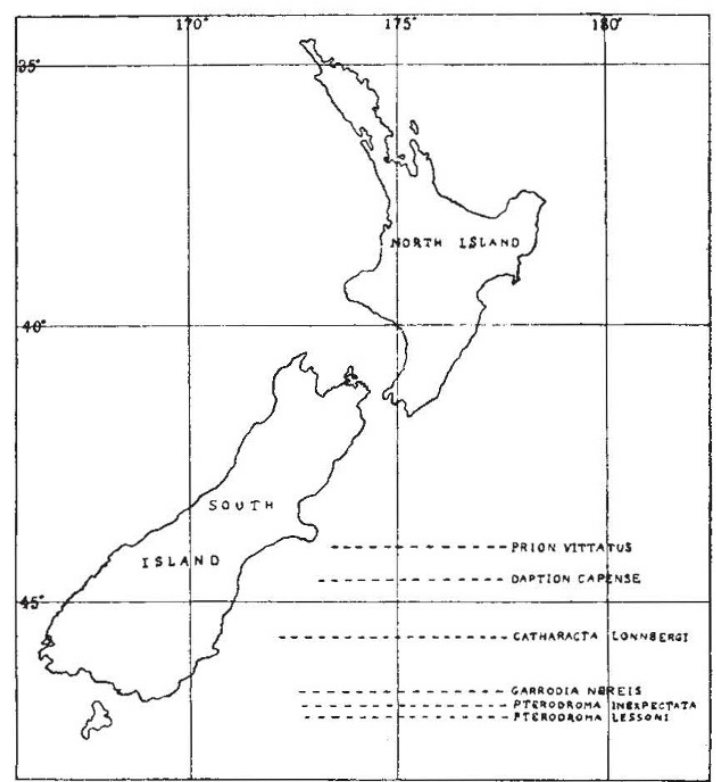

FIG. 2,-Map showing the northern limit for southern breeding species of birds.

which is the height of the breeding season, and that the position of suitable breeding islands must have some influence on distribution at this time.

The observed species will be divided into two groups, namely, the northern breeding species and the southern breeding species. To the first-named group belong birds breeding on the north island of New Zealand and the small islets lying north of this, and the last-named group comprises species breeding on the south island of New Zealand or on islands in more southern latitudes.

We will first consider the distribution of the northern breeding species, and the chart, Fig. 1, shows approximately the southern limit for the occurrence of these birds in the open sea.* North of the lines indicated the different species are seen more or less frequently, while these species are not observed south of the respective lines. It will be seen that the two species, the pale-footed Shearwater (Puffinus carneipes) and Cook's Petrel (Pterodroma cooki), both of which were observed in large numbers in the waters round the north coast of the north island, already ceased to appear when we passed off the East Cape (about $38^{\circ}$ S.). Both species are also only known to breed on islets north of this point. Other northern breeding species extend their distribution more to the south. In Cook Strait we thus found the southern limit

* In regard to the systematic names I refer to " Birds of the Ocean" by W. B. Alexander (G. P. Putnam's Sons, New York and London, 1928), a book which has given me the most valuable assistance in my 1928 , a book which has given me the most valuable assistance
ornithological observations during this cruise with the Dana.

No. 3173, VoL. 126] 
for the appearance of the white-faced Storm-Petrel (Pelagodroma marina), but in regard to this species it must be mentioned that its breeding area is not restricted only to the north island of New Zealand, as it is also noted as breeding on Chatham Island and Auckland Island (cf. W. B. Alexander, p. 92). The southern limit shown, therefore, apparently only accounts for the New Zealand breeding specimens of this species. A little more to the south (about $42^{\circ} \mathrm{S}$.) we find the most southern occurrence of the great-winged Petrel (Pterodroma macroptera), and the grey-backed Shearwater (Puffinus bulleri) is observed so far south as off Banks Peninsula (about $44^{\circ} \mathrm{S}$.). Both the two lastnamed species are in these regions only found breeding on the north island of New Zealand and surrounding islets.

As we gradually came more to the south we met several species of birds at sea, which we had not observed before, and all these species were breeding on the south island of New Zealand or in more southern latitudes. The northern limit of the southern breeding species in this month of the year was found about $44^{\circ}$ S., as will be seen on Fig. 2 .

Off Banks Peninsula we thus met the first specimen of the broad-billed Prion (Prion vittatus), which is recorded as breeding on Stewart Island and Chatham Island, but elsewhere on islands under more southern latitudes. A little more to the south we fixed the northern limit for the Pintado Petrel or 'Cape Pigeon' (Daption capense), as this species is commonly called by sailors. The nearest known breeding-place for this species is Antarctica, although it probably occurs at the Snares and other sub-antarctic islands. About $45^{\circ}-46^{\circ}$ S. Lat. the first specimen of the dark Skua (Catharacta lönnbergi) was observed. This species, which is recorded as breeding on the south island of New Zealand, appeared always singly. In the most southern part of the area investigated - between $46^{\circ}$ and $47^{\circ} \mathrm{S}$. Lat.-we further noted other species, which are only known breeding on South Island or in the sub-antarctic islands of New Zealand. These were the following: the grey-backed Storm-Petrel (Garrodia nereis), Peale's Petrel (Pterodroma inexpectata), and the whiteheaded Petrel (Pterodroma lessoni), all of which only appeared as single specimens. In most cases the largest numbers of birds were observed. during the morning and the forenoon, and nearly all were flying in an easterly direction, presumably indicating that it was breeding birds making seaward from land.

In connexion with the recorded observations of oceanic birds it is of interest to look at the surface temperatures in the waters east of New Zealand, as found during our trip in the month of January 1929.

It will be seen from the chart (Fig. 3) that the surface temperature is decreasing in a rather high degree from north to south, namely, in the investigated area, from more than $19^{\circ}$ to less than $13^{\circ} \mathrm{C}$. It is the cold antarctic water, which here advances along the east coast of New Zealand. The isotherms are based on rather few observations and only on this single cruise, but they seem to indicate that the temperature especially is quickly decreas. ing from $17^{\circ}$ to $14^{\circ} \mathrm{C}$. This is the case between $42^{\circ}$ and $44^{\circ}$ south latitude, and it is just in this area that we found in most cases the' southern limit for the northern breeding species and the northern limit for the southern breeding species of sea-birds. The marine biological investigations on board the Dana along the east coast of New Zealand also demonstrated a very great difference in the composition and kind of plankton on the way from north to south. Thus we found

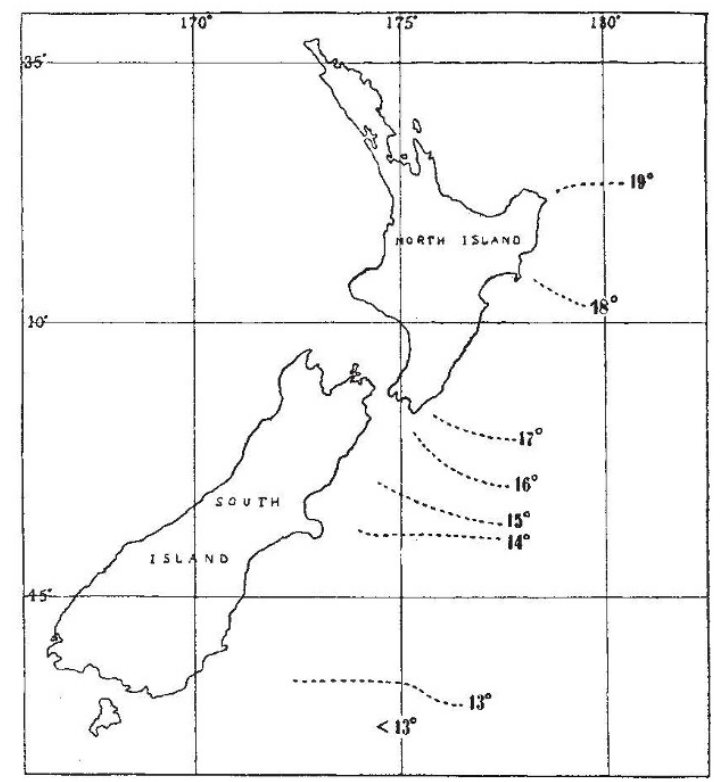

FxG. 3.- Map showing the surface temperatures in the waters east of New Zealand on the cruise of the Danish Research Ship Dana, Jan. 2-13, 1929.

the plankton more and more characteristic of the colder water when we were going south, and on the most southerly stations the plankton had in many ways certain resemblances to that in the waters round Iceland and the Faroe Islands in the North Atlantic. Due to the different temperatures in the water the food for the birds living over the high sea thus will be different in the various latitudes, and therefore the surface temperature of the water, in an indirect way anyhow, is a factor of great importance in regard to the distribution of various sea-birds in these waters.

From the above-mentioned observations it will be understood that the composition of the birdlife is quite different in the northern and in the southern parts of the investigated area, but for certain species of sea-birds it has not been possible within this area to determine limits for their distribution. Two species of Albatross (Diomedea exulans and Thalassarche melanophrys) and the Giant Petrel (Macronectes giganteus) - - the nearest breeding-places for these are presumably the sub-antarctic islands south of New Zealand--we thus met a little north of New Zealand and within the whole investigated area, and the Fluttering Shearwater (Puffinus gavia) 
which is found breeding both on North and South Island and on the Snares south of New Zealand was recorded rather near land along the coast of both the north and the south island. Furthermore, it may be mentioned that the Sooty Shearwater (Puffinus griseus), which is known to breed on both the New Zealand islands, on the south-going trip was seen about $44^{\circ}$ south latitude, but during the following part of the route, as well as in
Cook Strait, the species was observed daily and sometimes in large numbers.

To complete the list of more oceanic birds which were observed and determined with certainty during this cruise, it may be mentioned that several specimens of the Fairy Prion (Pachyptila turtur) and the Little Penguin (Eudyptula minor) were observed during the passage through the Hauraki Gulf as well as in Cook Strait.

\section{Competition between Plants.*}

$\mathrm{T}$ $\mathrm{HE}$ recent publication of the work of Clements, Weaver, and Hanson, on "Plant Competition " reports the results of numerous experiments designed to analyse the competitive functions in plant communities. Many of these consisted of transplantations of species characteristic of one phase of a succession into a type of vegetation representing an earlier or later phase. In view of the fact that the major mortality amongst plants would appear to be in the juvenile stage of development (cf. Nature, May 31, p. 817), conclusions based upon transplantations of established plants must obviously be accepted with considerable reservation when evaluating the competitive relations between species, but recognising these limitations such have considerable value.

In a recent address (Journal of Ecology, August 1929) the reviewer, dealing with the biological equipment of species in relation to competition, emphasised the importance as factors in the competition struggle of such features, inter alia, as potential height, rate of growth and spread, development of the root system, capacity for reproduction, and the mode and percentage of germination. The experiments of Prof. Clements and his collaborators furnish additional corroboration of these conclusions. They state that practically all the advantages or weapons of species are epitomised in the two words amount and rate. In competition between short and tall grasses the latter were successful under moist conditions, but under dry conditions or when the herbage was grazed the shorter grasses, as might be expected, more than held their own. Sporobolus asper was successful in competition with Andropogon furcatus, despite its shorter stature, a result attributed to its more efficient root system. Elymus canadensis is the victor in the struggle with Panicum virgatum owing probably to the earlier and more rapid growth of the former.

The importance of percentage germination was shown by cultures of Andropogon glaucum with Andropogon scoparius, in which it was found that either species became the dominant when the number of its seedlings had been considerably in excess of those of the other. The advantage of priority of occupation was shown by transplantation experiments, in which it was found that the species already established were almost always victorious over those introduced-a conclusion

* PJant Competition: An Analysis of Community Functions, by F. E. Clements, J. E. Weaver, and H. C. Hanson. Pp. xvi +340 , with 32 Plates, 30 Figs., and 133 Tables. (Washington, D.C.: Carnegie Institution, 1929.)

No. 3173 , VoL. 126] which supports the contention that mass migration rather than random inoculation is the important factor for successful establishment.

Experiments upon the competition between forest and prairie show the importance of moisture in favouring the arboreal vegetation. The transition zone between the grassland and forest is a broad one of fluctuating extent, and the hypothesis is put forward that the advance or retreat of the forest margin respectively corresponds to the wet and dry climatic phases which coincide with the sunspot cycle.

The observations of Cockayne in New Zealand, and of other experienced field botanists, have emphasised the absence of naturalised species from virgin climax communities in regions where disturbed vegetation has become invaded by an extensive alien flora. Denudation experiments also bear witness to the importance of priority of occupation in the plant world. Cornfields which have passed out of cultivation may still show remains of the weed flora thirty-five years after they have ceased to be arable land, whilst wood-anemones and other members of the shade-flora will persist long after a woodland area has been converted into pasture. Such persistence is indicative of the comparative stability of plant communities and shows that the pressure of oompetition may operate over a considerable period before its effects are manifest. For this reason the drastic changes involved in many competition experiments, such as those here considered, which operate within a brief period of but a few years at most, are probably not directly comparable to the competitive processes of Nature, which if sure in their outcome are often extremely slow in their manifestation. Nevertheless, the amount of experimental work bearing on the phenomenon of competition is so meagre that we welcome the publication of any such studies whilst recognising the caution necessary in applying conclusions based on these artificial conditions to the explanation of competition phenomena as they occur in Nature.

The work is more of a very detailed account of the experiments than, as might be inferred from the title, a general résumé of the subject, and indeed one is conscious of a sense of inadequacy due, in part, to a lack of coherence in the method of presentation and, in part, to the omission of data necessary to the proper appreciation by the reader of the real significance of these experiments.

\section{E. J. Salisbury.}

